\title{
The impact of hospital harm on length of stay, costs of care and length of person-centred episodes of care: a retrospective cohort study
}

\author{
Lauren Tessier HBSc, Sara J.T. Guilcher PT PhD, Yu Qing Bai MSc, Ryan Ng MSc, Walter P. Wodchis PhD
}

Cite as: CMAJ 2019 August 12;191:E879-85. doi: 10.1503/cmaj.181621

Visual abstract available at www.cmaj.ca/lookup/suppl/doi:10.1503/cmaj.181621/-/DC2

See related article at www.cmaj.ca/lookup/doi/10.1503/cmaj.190912

\section{ABSTRACT \\ BACKGROUND: There is a lack of data in Canada on the longitudinal effects of adverse events that occur in hospital, spe- cifically in the period after discharge. Our objective was to quantify the impact of adverse events on hospital length of stay, length of person-centred episodes of care (PCEs) and costs of PCEs, as well as their impact on the total health system.}

METHODS: We conducted a populationbased, retrospective cohort study using linked health administrative databases. We included adults in Ontario who had an acute hospital admission between Apr. 1, 2015, and Mar. 31, 2016. We grouped hospital admissions into 1 of 9 episode types and used the Canadian Institute for Health Information methodology for hospital harm to measure adverse events. We specified generalized linear models to estimate the impact of hospital harm on the following: incremental length of index acute hospital admission, incremental length of the PCE, and incremental costs of the PCE.

RESULTS: Out of 610979 hospital admissions, 36004 (5.9\%) involved an occurrence of harm. The impact of harm on the incremental length of hospital stay ranged from 0.4 to 24.2 days $(p<0.001)$; the incremental length of the PCE ranged from 0.3 to 30.2 days $(p<0.001)$; and the incremental costs of the PCE ranged from $\$ 800$ to $\$ 51067(p<0.001)$. Total hospital days attributable to hospital harm amounted to 407696, and the total attributable cost to the Ontario health system amounted to $\$ 1088330376$.

INTERPRETATION: We found that experiencing harm in hospital significantly affects both in-hospital and postdischarge use of health services and costs of care, and constitutes an enormous expense to Ontario's publicly funded health system.
$\mathrm{P}$ atient safety is a key component of high-quality health care delivery as well as an expectation among patients and caregivers. Substantial interest in improving patient safety was prompted following the release of the Institute of Medicine's seminal report, To Err is Human, ${ }^{1}$ which estimated that between 44000 and 98000 Americans died each year as a result of medical mistakes, with an associated cost between US\$17 billion and \$29 billion. The Canadian Adverse Events Study followed shortly thereafter and estimated that, in 2000, about 185000 hospital admissions were associated with an adverse event, and close to 70000 of these were potentially preventable. ${ }^{2}$ Despite the substantial attention these findings generated and the policy initiatives they inspired, ${ }^{3,4}$ hospital-based adverse events remain a prevalent issue., ${ }^{5,6}$ Recently, the Canadian
Institute for Health Information (CIHI) partnered with the Canadian Patient Safety Institute to develop a measure of adverse events in hospital - termed "hospital harm" - using administrative health data. ${ }^{7}$ This measure is analogous to the Agency for Healthcare Research and Quality's Patient Safety Indicators ${ }^{8,9}$ and enables a renewed attention on surveillance of patient safety specific to a Canadian setting.

Although it is understood that experiencing harm in hospital increases length of hospital stay, ${ }^{5,9,10}$ costs of hospital care, ${ }^{9-17}$ risk of death ${ }^{9,11,14}$ and risk of re-admission, ${ }^{11,14}$ there is a lack of information on the relation between hospital harm and total cost inclusive of postdischarge use of health services and accompanying costs. ${ }^{14}$

In this study, our objective was to assess the impact of hospital harm on the incremental length of hospital stay, as well as on 
the incremental duration and cost of person-centred episodes of care (PCEs), inclusive of acute and postacute care. ${ }^{18}$ We additionally sought to assess the total health system impact associated with hospital harm. The PCE methodology creates episodes of care that span acute and postacute care and aligns itself with renewed efforts to draw attention away from sector-specific costs to focus on episodes of care and enable value-based evaluation of health care. ${ }^{18,19}$ We hypothesized that hospital harm would lead to significant incremental and total attributable increases in the outcomes of interest.

\section{Methods}

\section{Setting and data}

We conducted a population-based, retrospective cohort study in Ontario, Canada, using health administrative databases at ICES. These data are inclusive of all hospital, physician, pharmaceutical, laboratory, home care and long-term care paid for by the Ontario Ministry of Health and Long-Term Care. All records were linked sequentially for each study patient by use of encrypted health card numbers. A description of these databases appears in Appendix 1A (Appendix 1, available at www.cmaj.ca/lookup/ suppl/doi:10.1503/cmaj.181621/-/DC1). Ontario's health administrative data have been shown to be both valid and reliable, ${ }^{20}$ and have been used previously to estimate medical $\operatorname{costs}^{21}$ and study patterns of health services use. ${ }^{18,21-25}$

\section{Patients}

We used PCEs to identify individuals eligible for study inclusion. The complete PCE methodology has been described in detail previously. ${ }^{18}$ Briefly, a PCE is defined as beginning with an acute hospital admission and includes subsequent care until an individual has returned to the community and is stabilized for 30 days without any institutional admissions. ${ }^{18}$ Person-centred episodes of care are classified according to the clinical grouping for the initial admission and are mutually exclusive. Patients aged 18-105 years on the study index date (Apr. 1, 2015) and eligible for coverage under the Ontario Health Insurance Plan at the time of hospital admission were included. To be eligible for study inclusion, patients had to be discharged alive from an acute hospital admission between Apr. 1, 2015, and Mar. 31, 2016, with a minimum length of stay of 24 hours in one of the following mutually exclusive PCEs of interest: pregnancy, trauma, mental health, cancer, renal, planned surgical, planned medical, unplanned surgical or unplanned medical. Appendix 1B (Appendix 1) contains the full list of exclusions.

\section{Exposure}

Our main exposure was the occurrence of a hospital harm in patients' first acute hospital admission in the period between Apr. 1, 2015, and Mar. 31, 2016. We identified hospital harm using the $\mathrm{CIHI}$ hospital harm methodology. ${ }^{7}$ The $\mathrm{ClHI}$ defines hospital harm as a hospital admission in which a patient experiences at least 1 unintended occurrence of harm that is potentially preventable by implementing known evidence-informed safety practices. ${ }^{7}$ The methodology consists of 4 major categories of harm that encompass 31 groupings of harmful events. The 4 categories of harm are health care- or medication-associated conditions, health care-associated infections, patient accidents, and procedureassociated conditions. ${ }^{7}$ The hospital harm framework employs International Statistical Classification of Diseases and Related Health Problems, 10th Revision, Canada codes recorded in the Discharge Abstract Database to identify hospital admissions in which hospital harm occurred. In developing the hospital harm indicator, $\mathrm{ClHI}$ ensured a comprehensive data assurance program and included additional steps to determine how useful administrative data were for measuring the occurrence of harm in hospital, including validation of facility-level results by hospitals across Canada. ${ }^{7,26}$

\section{Outcomes}

The primary outcomes of this study were the incremental length of acute index hospital stay, duration of the PCE, and costs of the PCE attributable to hospital harm. Length of hospital stay and length of the PCE were measured in days. To measure costs, all records of health care use paid for by the Ontario Ministry of Health and Long-term Care during a PCE were retrieved. The cost associated with each use of health care services was estimated and aggregated over the PCE by use of costing methods developed for health administrative data that have previously been described. ${ }^{27,28}$ Costs are reported in 2017 Canadian dollars. We report total attributable acute days, total attributable length of PCEs and total attributable costs of PCEs.

\section{Covariates}

We measured several covariates that were hypothesized as confounders in the relation between hospital harm and the outcomes of interest: age, sex, PCE type, neighbourhood income quintile, location of residence, rurality, number of chronic conditions $(0,1,2,3,4, \geq 5)$, major clinical category (most responsible diagnosis or intervention that substantially affects the pattern of care and resources consumed by a patient), Hospital Frailty Risk Score $^{29}(<5,5-15,>15)$, previous emergency department visits and hospital admissions 1 year before index, hospital type (teaching or community), and postadmission conditions. An interaction term between PCE type and hospital harm was also included. Postadmission conditions are mutually exclusive from the hospital harm indicator and capture conditions reported in previous studies of patient safety. ${ }^{16}$ A further discussion of the included covariates appears in Appendix 1C (Appendix 1).

\section{Statistical analysis}

We compared baseline characteristics of patients who experienced hospital harm and patients who did not using standardized differences. A standardized difference less than 0.10 was considered negligible. ${ }^{30}$ To obtain the best fit to our data, we use regression models and specified generalized linear models with a log link and $\gamma$ distribution to estimate the incremental effect of hospital harm on length of index hospital stay, duration of PCE, and costs of PCE (following the approach and results of tests recommended by Manning and Mullahy ${ }^{31}$ for cost). ${ }^{32}$

Based on this regression, we estimated a prediction of each outcome in patients who did and did not experience hospital 
harm, and we used this difference to measure incremental outcomes. The difference between groups (those who experienced hospital harm and those who did not) was assessed via 2-tailed $t$ tests. We then calculated the total system impact of hospital harm in terms of total attributable acute days, total attributable PCE days, and total attributable costs per PCE. A $p$ value less than 0.05 was taken to indicate differences of hospital harm effects across groups. ${ }^{33}$ Further subgroup analyses were conducted by age ( $<65$ and $\geq 65 \mathrm{yr}$ ). Formal testing with interaction $p$ values was conducted in considering subgroup differences.

As a sensitivity analysis, we excluded patients with electrolyte and fluid imbalance and also those who developed sepsis after their index admission from the count of patients who experienced a hospital harm, as the status of these as potentially preventable has been contested. We removed the indicator for postadmission conditions from the models as a final sensitivity analysis.

All analyses were performed using SAS Enterprise Guide 7.1.

\section{Ethics approval}

The use of data in this project was authorized under section 45 of Ontario's Personal Health Information Protection Act, which does not require review by a research ethics board.

\section{Results}

We identified a total of 610979 patients eligible for study inclusion. Characteristics of patients who experienced hospital harm and those who did not appear in Table 1. The largest volume of cases was for unplanned medical PCE (32.3\%), whereas renal PCE represented the smallest proportion of cases $(0.8 \%)$. A breakdown of the cohort by PCE category appears in Appendix 1D (Appendix 1).

Of the 610979 patients included in the study, 36004 (5.9\%) experienced a hospital harm in their index acute hospital admission. Among patients who experienced a hospital harm, the largest number of patients were admitted for an unplanned medical PCE (24.6\%). The incidence of hospital harm within PCEs was highest overall in the trauma PCE (14.1\%) and lowest in the mental health PCE (0.6\%) (results not shown). Health care- or medication-associated conditions represented the most frequent harm category overall (50.1\%).

After adjusting for confounders, we found that the incremental length of hospital stay attributable to hospital harm ranged from 0.4 days (pregnancy PCE) to 24.2 days (mental health PCE). The incremental duration of PCE ranged from 0.3 days (pregnancy PCE) to 30.2 days (trauma PCE). Finally, the incremental costs of PCE ranged from $\$ 800$ (pregnancy PCE) to $\$ 51067$ (unplanned surgical PCE). The incremental length of hospital stay, duration of PCE and costs of PCE were significant in all PCE categories $(p<0.001)$. The full results are shown in Table 2. Results from the multivariable regression analyses appear in Appendices 1E-1G (Appendix 1).

Summing across all PCE categories, the total incremental acute days attributable to hospital harm amounted to
407696 days; the total incremental PCE days amounted to 661646 days; and the total incremental costs amounted to \$1088330376 (Table 3).

In our first subgroup analysis by age, hospital harm significantly increased length of hospital stay and costs of PCE for both patients younger than 65 years $(p<0.001)$ and patients aged 65 years and older $(p<0.001)$. In patients younger than 65 years, duration of PCE was significantly increased $(p<0.001 ; p=0.01$ for unplanned surgical PCE) in all PCEs among those who experienced hospital harm, aside from those in the mental health PCE $(p=0.6)$. Experiencing a hospital harm significantly increased duration of PCE in patients aged 65 years and older $(p<0.001)$.

When we excluded patients with electrolyte and fluid imbalance and those with sepsis (undertaken as separate analyses), the impact of hospital harm on length of stay, duration of PCE and costs of PCE remained consistent and significant. Finally, on removal of the indicator for postadmission conditions, our results also remained consistent and significant. When included as a covariate, the effect of all other postadmission conditions was significant for all outcomes $(p<0.001)$ but much smaller than the effect of hospital harm.

\section{Interpretation}

In this population-based study, we measured the attributable length of hospital stay, duration of first PCE, and cost of first PCE in patients who experienced a hospital harm during their acute hospital admission in 1 of 9 PCE catoegories. Of the 610979 patients included in this study, 36004 (5.9\%) experienced a hospital harm. The attributable length of hospital stay related to experiencing a hospital harm was highest in the mental health PCE, at 24.2 days. The duration of PCE attributable to experiencing a hospital harm was highest in the trauma PCE, at 30.2 days. The incremental cost of PCE attributable to experiencing a hospital harm was highest in the unplanned surgical PCE, at $\$ 51067$. Overall, the health system impact of hospital harm amounted to a total of an incremental 407696 hospital days, 661646 PCE days and a cost of $\$ 1088330376$ for the province of Ontario.

Our overall incidence rate of hospital harm of $5.9 \%$ is similar to the national incidence rates of $5.6 \%$ reported recently by $\mathrm{CIHI}$ and $7.5 \%$ in 2004 by Baker and colleagues in the Canadian Adverse Events Study. ${ }^{2,7}$ Our finding that hospital harm significantly increases length of PCE adds to the literature, as the PCE methodology has only recently been developed..$^{18}$ Its use here is timely, as health care systems are increasingly moving toward value-based care that is based on purchasing not only isolated health provider encounters but the outcome produced by all providers centred around a particular health episode. The PCE methodology enables all acute and postacute care, including hospital, physician, pharmacy and home care re-admissions to be captured in the episode of care, an important advance as many of the studies on the costs of adverse events have treated readmissions as initial admissions, leading to bias. ${ }^{11}$ More importantly, the use of PCEs highlights that the effects of experiencing harm in hospital extend to the postdischarge period, supporting earlier results from the United States and Denmark. ${ }^{14,17}$ 
Table 1: Baseline characteristics of 610979 patients, by hospital harm status

\begin{tabular}{|c|c|c|c|}
\hline \multirow[b]{2}{*}{ Characteristic } & \multicolumn{2}{|c|}{ No. $(\%)$ of patients* } & \multirow[b]{2}{*}{$\begin{array}{l}\text { Standardized } \\
\text { difference }\end{array}$} \\
\hline & $\begin{array}{l}\text { Hospital harm } \\
\qquad n=36004\end{array}$ & $\begin{array}{l}\text { No hospital harm } \\
n=574975\end{array}$ & \\
\hline Age, yr, mean \pm SD & $64.88 \pm 19.83$ & $55.94 \pm 21.02$ & 0.44 \\
\hline Sex, female & $20282(56.3)$ & 350975 (61.0) & 0.10 \\
\hline \multicolumn{4}{|l|}{ Neighbourhood income quintile } \\
\hline Q1 (lowest) & $8571(23.8)$ & $136070(23.7)$ & 0.00 \\
\hline Q2 & $7972(22.1)$ & $121293(21.1)$ & 0.03 \\
\hline Q3 & 7150 (19.9) & $113086(19.7)$ & 0.00 \\
\hline Q4 & $6231(17.3)$ & $104643(18.2)$ & 0.02 \\
\hline Q5 (highest) & $6015(16.7)$ & $98954(17.2)$ & 0.01 \\
\hline Rural residence & $4034(11.2)$ & $72331(12.6)$ & 0.04 \\
\hline \multicolumn{4}{|l|}{ No. of chronic conditions } \\
\hline 0 & $11288(31.4)$ & $129606(22.5)$ & 0.20 \\
\hline 1 & $3170(8.8)$ & $91936(16.0)$ & 0.22 \\
\hline 2 & $3441(9.6)$ & $88306(15.4)$ & 0.18 \\
\hline 3 & $3959(11.0)$ & $79057(13.7)$ & 0.08 \\
\hline 4 & $4152(11.5)$ & $63977(11.1)$ & 0.01 \\
\hline$\geq 5$ & $9994(27.8)$ & $122093(21.2)$ & 0.15 \\
\hline Major clinical category, intervention $†$ & $18256(50.7)$ & $224466(39.0)$ & 0.24 \\
\hline \multicolumn{4}{|l|}{ Hospital Frailty Risk Score ${ }^{29}$} \\
\hline Low risk (<5) & $29186(81.1)$ & $564046(98.1)$ & 0.58 \\
\hline Intermediate (5-15)/high risk (> 15) & $6818(18.9)$ & $10929(1.9)$ & 0.58 \\
\hline Teaching hospital & $14844(41.2)$ & $176176(30.6)$ & 0.22 \\
\hline Postadmission conditions, yes & - & $47025(8.2)$ & - \\
\hline \multicolumn{4}{|l|}{ PCE category } \\
\hline Pregnancy & $4524(12.6)$ & $117361(20.4)$ & 0.21 \\
\hline Trauma & $6175(17.2)$ & $37774(6.6)$ & 0.33 \\
\hline Mental health & $229(0.6)$ & $38404(6.7)$ & 0.33 \\
\hline Cancer & $4284(11.9)$ & $34153(5.9)$ & 0.21 \\
\hline Renal & $425(1.2)$ & $4314(0.7)$ & 0.04 \\
\hline Planned surgical & $6080(16.9)$ & $104131(18.1)$ & 0.03 \\
\hline Planned medical & $183(0.5)$ & $5359(0.9)$ & 0.05 \\
\hline Unplanned surgical & $5237(14.5)$ & $45212(7.9)$ & 0.21 \\
\hline Unplanned medical & $8867(24.6)$ & $188267(32.7)$ & 0.18 \\
\hline \multicolumn{4}{|l|}{ Harm category } \\
\hline Health care- or medication-associated conditions & $18027(50.1)$ & - & - \\
\hline Health care-associated infections & $13328(37.0)$ & - & - \\
\hline Patient accidents & $967(2.7)$ & - & - \\
\hline Procedure-associated conditions & $9819(27.3)$ & - & - \\
\hline $\begin{array}{l}\text { No. of hospital admissions within } 1 \mathrm{yr} \text { before index } \\
\text { admission, mean } \pm \text { SD }\end{array}$ & $0.30 \pm 0.82$ & $0.22 \pm 0.70$ & 0.11 \\
\hline $\begin{array}{l}\text { No. of ED visits within } 1 \mathrm{yr} \text { before index admission, } \\
\text { mean } \pm S D\end{array}$ & $1.30 \pm 2.36$ & $1.31 \pm 2.99$ & 0.01 \\
\hline \multicolumn{4}{|c|}{$\begin{array}{l}\text { Note: } E D=\text { emergency department, } P C E=\text { person-centred episodes of care, } \mathrm{SD}=\text { standard deviation. } \\
\text { *Unless stated otherwise. } \\
\text { †International Statistical Classification of Diseases and Related Health Problems, } 10 \text { th Revision, Canada diagnosis codes are used to categorize patients into } \\
\text { major clinical categories. These broad categories are based on the most responsible diagnosis code. This diagnosis is the one determined to have been } \\
\text { responsible for the greatest portion of the patient's length of stay. Major clinical categories are divided into } 2 \text { partitions: intervention and diagnosis. } \\
\ddagger \text { Because of small cell counts in those deemed high risk based on Hospital Frailty Risk Score, intermediate and high-risk groups were combined. }\end{array}$} \\
\hline
\end{tabular}




\section{Limitations}

The $\mathrm{ClHI}$ hospital harm methodology does not capture all harmful events that occur in hospital; only harms identified as potentially preventable are included. ${ }^{7}$ A more comprehensive list of the types of harm not captured by the methodology is described elsewhere. ${ }^{7}$ It should be stressed that while the methodology aims to identify only potentially preventable instances of harm, not all instances of harm actually are preventable. In a recent review on adverse events in health care, it was reported that between one- and two-thirds of hospital adverse events are estimated to be preventable. ${ }^{34}$ Such estimates have implications for the results of this study. If only two-thirds of cases of the hospital

\begin{tabular}{|c|c|c|c|c|c|c|c|c|c|c|c|c|}
\hline \multirow[b]{2}{*}{$\begin{array}{l}\text { PCE } \\
\text { category }\end{array}$} & \multicolumn{3}{|c|}{$\begin{array}{l}\text { Length of hospital stay, d, } \\
\text { mean } \pm \text { SD }\end{array}$} & \multirow[b]{2}{*}{$\begin{array}{c}p \\
\text { value }\end{array}$} & \multicolumn{3}{|c|}{$\begin{array}{l}\text { Duration of first PCE, d, } \\
\text { mean } \pm \text { SD }\end{array}$} & \multicolumn{4}{|c|}{$\begin{array}{c}\text { Cost of first PCE, } 2017 \text { Can\$, } \\
\text { mean } \pm \text { SD }\end{array}$} & \multirow[b]{2}{*}{$\begin{array}{c}p \\
\text { value }\end{array}$} \\
\hline & $\begin{array}{l}\text { Hospital } \\
\text { harm }\end{array}$ & $\begin{array}{c}\text { No } \\
\text { hospital } \\
\text { harm }\end{array}$ & Incremental & & $\begin{array}{l}\text { Hospital } \\
\text { harm }\end{array}$ & $\begin{array}{c}\text { No } \\
\text { hospital } \\
\text { harm }\end{array}$ & Incremental & $\begin{array}{c}p \\
\text { value }\end{array}$ & $\begin{array}{l}\text { Hospital } \\
\text { harm }\end{array}$ & $\begin{array}{c}\text { No } \\
\text { hospital } \\
\text { harm }\end{array}$ & Incremental & \\
\hline Pregnancy & $3.5 \pm 0.3$ & $3.1 \pm 0.3$ & $0.4 \pm 0.3$ & $<0.001$ & $\begin{array}{c}35.0 \pm \\
1.6\end{array}$ & $34.6 \pm 2.0$ & $0.3 \pm 2.0$ & $<0.001$ & $\begin{array}{l}6172 \\
\pm 896\end{array}$ & $5373 \pm 909$ & $800 \pm 909$ & $<0.001$ \\
\hline Trauma & $\begin{array}{c}25.0 \pm \\
10.2\end{array}$ & $7.7 \pm 2.9$ & $17.3 \pm 4.9$ & $<0.001$ & $\begin{array}{c}82.0 \pm \\
16.3\end{array}$ & $\begin{array}{c}51.8 \\
\pm 11.6\end{array}$ & $30.2 \pm 12.5$ & $<0.001$ & $\begin{array}{r}70556 \\
\pm 28063\end{array}$ & $\begin{array}{l}22732 \\
\pm 8496\end{array}$ & $\begin{array}{c}47824 \pm \\
13732\end{array}$ & $<0.001$ \\
\hline $\begin{array}{l}\text { Mental } \\
\text { health }\end{array}$ & $\begin{array}{c}34.3 \pm \\
12.8\end{array}$ & $\begin{array}{c}10.1 \pm \\
4.0\end{array}$ & $24.2 \pm 4.6$ & $<0.001$ & $\begin{array}{c}85.2 \pm \\
23.7\end{array}$ & $\begin{array}{c}58.0 \\
\pm 43.4\end{array}$ & $27.2 \pm 42.9$ & $<0.001$ & $\begin{array}{c}43693 \\
\pm 16913\end{array}$ & $\begin{array}{c}25679 \\
\pm 17502\end{array}$ & $\begin{array}{c}18014 \pm \\
17481\end{array}$ & $<0.001$ \\
\hline Cancer & $\begin{array}{c}18.0 \pm \\
5.7\end{array}$ & $6.5 \pm 1.1$ & $11.5 \pm 2.3$ & $<0.001$ & $\begin{array}{c}62.9 \pm \\
8.5\end{array}$ & $46.2 \pm 4.5$ & $16.7 \pm 5.2$ & $<0.001$ & $\begin{array}{r}48775 \\
\pm 15086\end{array}$ & $\begin{array}{l}21424 \\
\pm 4686\end{array}$ & $27351 \pm 6879$ & $<0.001$ \\
\hline Renal & $\begin{array}{c}19.6 \pm \\
7.9\end{array}$ & $8.2 \pm 3.0$ & $11.4 \pm 3.8$ & $<0.001$ & $\begin{array}{c}68.2 \pm \\
12.6\end{array}$ & $\begin{array}{c}52.7 \\
\pm 16.8\end{array}$ & $15.6 \pm 16.4$ & $<0.001$ & $\begin{array}{c}49732 \\
\pm 18458\end{array}$ & $\begin{array}{l}23421 \\
\pm 8406\end{array}$ & $26311 \pm 9913$ & $<0.001$ \\
\hline $\begin{array}{l}\text { Planned } \\
\text { surgical }\end{array}$ & $\begin{array}{c}10.6 \pm \\
3.0\end{array}$ & $3.7 \pm 0.5$ & $6.9 \pm 0.9$ & $<0.001$ & $\begin{array}{l}51.0 \pm \\
6.5\end{array}$ & $37.3 \pm 3.7$ & $13.6 \pm 3.9$ & $<0.001$ & $\begin{array}{r}35406 \\
\pm 11033\end{array}$ & $\begin{array}{l}12375 \\
\pm 2551\end{array}$ & $23031 \pm 3699$ & $<0.001$ \\
\hline $\begin{array}{l}\text { Planned } \\
\text { medical }\end{array}$ & $\begin{array}{c}22.2 \pm \\
7.7\end{array}$ & $6.7 \pm 1.4$ & $15.5 \pm 2.0$ & $<0.001$ & $\begin{array}{c}75.8 \pm \\
11.7\end{array}$ & $\begin{array}{c}49.5 \\
\pm 11.6\end{array}$ & $26.3 \pm 11.6$ & $<0.001$ & $\begin{array}{c}51719 \\
\pm 16264\end{array}$ & $\begin{array}{l}18362 \\
\pm 5807\end{array}$ & $33357 \pm 6495$ & $<0.001$ \\
\hline $\begin{array}{l}\text { Unplanned } \\
\text { surgical }\end{array}$ & $\begin{array}{c}22.4 \pm \\
8.9\end{array}$ & $6.6 \pm 1.4$ & $15.8 \pm 3.3$ & $<0.001$ & $\begin{array}{c}71.3 \pm \\
13.2\end{array}$ & $\begin{array}{c}46.2 \\
\pm 313.5\end{array}$ & $25.1 \pm 294.1$ & $<0.001$ & $\begin{array}{c}70232 \\
\pm 28108\end{array}$ & $\begin{array}{c}19164 \pm \\
23636\end{array}$ & $\begin{array}{c}51067 \pm \\
24216\end{array}$ & $<0.001$ \\
\hline $\begin{array}{l}\text { Unplanned } \\
\text { medical }\end{array}$ & $\begin{array}{c}19.4 \pm \\
8.2\end{array}$ & $6.7 \pm 1.8$ & $12.7 \pm 2.5$ & $<0.001$ & $\begin{array}{c}67.1 \pm \\
17.5\end{array}$ & $\begin{array}{c}47.9 \pm \\
88.4\end{array}$ & $19.1 \pm 86.3$ & $<0.001$ & $\begin{array}{c}44353 \\
\pm 19146\end{array}$ & $\begin{array}{c}16909 \pm \\
11945\end{array}$ & $\begin{array}{c}27445 \pm \\
12396\end{array}$ & $<0.001$ \\
\hline
\end{tabular}

Note: $\mathrm{PCE}=$ person-centred episodes of care, $\mathrm{SD}=$ standard deviation.

${ }^{*}$ Incremental outcomes and $p$ values are adjusted by all the covariates of interest (Appendix 1, available at www.cmaj.ca/lookup/suppl/doi:10.1503/cmaj.181621/-/DC1).

Table 3: System impact during episodes of care associated with hospital harm during fiscal year 2015/16*

\begin{tabular}{|c|c|c|c|c|c|c|c|}
\hline \multirow[b]{2}{*}{ PCE category } & \multirow[b]{2}{*}{$\begin{array}{l}\text { No. of cases } \\
\text { of harm }\end{array}$} & \multicolumn{2}{|c|}{$\begin{array}{c}\text { Incremental acute } \\
\text { days }\end{array}$} & \multicolumn{2}{|c|}{$\begin{array}{c}\text { Incremental duration } \\
\text { of first PCE }\end{array}$} & \multicolumn{2}{|c|}{$\begin{array}{l}\text { Incremental cost of first } \\
\text { PCE, } 2017 \text { Can\$ }\end{array}$} \\
\hline & & $\begin{array}{l}\text { Days per } \\
\text { patient }\end{array}$ & $\begin{array}{l}\text { Total } \\
\text { days }\end{array}$ & $\begin{array}{l}\text { Days per } \\
\text { patient }\end{array}$ & $\begin{array}{l}\text { Total } \\
\text { days }\end{array}$ & $\begin{array}{l}\text { Cost per } \\
\text { patient }\end{array}$ & Total cost \\
\hline Pregnancy & 4524 & 0.38 & 1700 & 0.32 & 1468 & 800 & 3617540 \\
\hline Trauma & 6175 & 17.27 & 106645 & 30.21 & 186553 & 47824 & 295313077 \\
\hline Mental health & 229 & 24.23 & 5549 & 27.23 & 6235 & 18014 & 4125135 \\
\hline Cancer & 4284 & 11.50 & 49247 & 16.72 & 71618 & 27351 & 117169842 \\
\hline Renal & 425 & 11.39 & 4842 & 15.57 & 6619 & 26311 & 11182128 \\
\hline Planned surgical & 6080 & 6.89 & 41875 & 13.64 & 82941 & 23031 & 140027325 \\
\hline Planned medical & 183 & 15.55 & 2845 & 26.29 & 4811 & 33357 & 6104265 \\
\hline Unplanned surgical & 5237 & 15.80 & 82750 & 25.14 & 131679 & 51067 & 267439974 \\
\hline Unplanned medical & 8867 & 12.66 & 112244 & 19.14 & 169722 & 27445 & 243351091 \\
\hline Total & 36004 & 11.32 & 407696 & 18.38 & 661646 & 30228 & 1088330376 \\
\hline
\end{tabular}


harms measured in this study were preventable, the overall health system impact would be reduced to a total of 271798 hospital days, 441097 PCE days and $\$ 725553584$. This highlights that caution must be taken in interpreting these results and drawing conclusions about which events can feasibly be the targets of patient safety initiatives, as the method of defining hospital harm and attributing costs is designed to be inclusive, potentially leading to an overestimate. However, the $\mathrm{CIHI}$ hospital harm methodology aims to focus on potentially preventable events and excludes many postadmission hospital events (captured in our measure of other postadmission events). We undertook additional sensitivity analyses by excluding patients with electrolyte and fluid imbalance and those who developed sepsis after their index admission. Our results remained consistent and significant following both of these exclusions. Finally, there is a possibility that there may be unmeasured confounders, such as body mass index. This information is currently unavailable in administrative databases.

\section{Conclusion}

We found that experiencing hospital harm significantly increases length of hospital stay, length of PCE and costs of PCE. We employed the $\mathrm{CIHI}$ hospital harm methodology at a provincial level, which enabled us to estimate the total health system impact of hospital harm in Ontario. Financially, this amounted to \$1088330376 in 2017 Canadian dollars and 407696 acute hospital days or the equivalent of a 1117-bed hospital operating at $100 \%$ capacity between Apr. 1, 2015, and Mar. 31, 2016. Substantial investments in strategies to reduce adverse events could result in cost savings and additional benefits to patients. Future research should assess the impact of preventable harm on other outcomes, such as patient-reported outcomes, patient-reported experiences, re-admissions and death.

\section{References}

1. Institute of Medicine (US) Committee on Quality of Health Care in America. To err is human: building a safer health system. Kohn LT, Corrigan JM, Donaldson MS, editors. Washington (DC): National Academies Press (US); 2000. Available: www.ncbi.nlm.nih.gov/books/NBK225182 (accessed 2018 Oct. 23).

2. Baker GR, Norton PG, Flintoft V, et al. The Canadian Adverse Events Study: the incidence of adverse events among hospital patients in Canada. CMAJ 2004; 170:1678-86.

3. 5 Million Lives Campaign: overview. Boston: Institute for Healthcare Improvement. Available: www.ihi.org:80/Engage/Initiatives/Completed/5MillionLivesCampaign/ Pages/default.aspx (accessed 2018 Oct. 23).

4. Beyond the quick fix: strategies for improving patient safety. Toronto: Institute of Health Policy, Management and Evaluation, University of Toronto; 2015. Available: http://ihpme.utoronto.ca/wp-content/uploads/2015/11/Beyond -the-Quick-Fix-Baker-2015.pdf (accessed 2018 Apr. 30).

5. Forster AJ, Kyeremanteng K, Hooper J, et al. The impact of adverse events in the intensive care unit on hospital mortality and length of stay. BMC Health Serv Res 2008;8:259.

6. Wong BM, Dyal S, Etchells EE, et al. Application of a trigger tool in near real time to inform quality improvement activities: a prospective study in a general medicine ward. BMJ Qual Saf 2015;24:272-81.

7. Chan B, Cochrane D. Measuring patient harm in Canadian hospitals: What can be done to improve patient safety? Ottawa: Canadian Institute for Health Information, Canadian Patient Safety Institute; 2016. Available: www.cihi.ca/sites/ default/files/document/cihi_cpsi_hospital_harm_en.pdf (accessed 2018 Apr. 30).
8. Patient safety indicators overview. Rockville (MD): Agency for Healthcare Research and Quality. Available: www.qualityindicators.ahrq.gov/modules/ psi_overview.aspx (accessed 2018 Oct. 22).

9. Zhan C, Miller MR. Excess length of stay, charges, and mortality attributable to medical injuries during hospitalization. JAMA 2003;290:1868-74.

10. Hoogervorst-Schilp J, Langelaan M, Spreeuwenberg P, et al. Excess length of stay and economic consequences of adverse events in Dutch hospital patients. BMC Health Serv Res 2015;15:531.

11. Encinosa WE, Hellinger FJ. What happens after a patient safety event? Medical expenditures and outcomes in medicare. In: Henriksen K, Battles JB, Marks ES, et al, editors. Advances in patient safety: from research to implementation (volume 1: research findings). Rockville (MD): Agency for Healthcare Research and Quality (US); 2005. Available: www.ncbi.nlm.nih.gov/books/NBK20457 (accessed 2018 May 1).

12. Zhan C, Friedman B, Mosso A, et al. Medicare payment for selected adverse events: building the business case for investing in patient safety. Health Aff (Millwood) 2006;25:1386-93

13. Kaushal R, Bates DW, Franz C, et al. Costs of adverse events in intensive care units. Crit Care Med 2007;35:2479-83.

14. Encinosa WE, Hellinger FJ. The impact of medical errors on ninety-day costs and outcomes: an examination of surgical patients. Health Serv Res 2008;43: 2067-85.

15. Jackson T. One dollar in seven: scoping the economics of patient safety. Ottawa: Canadian Patient Safety Institute; 2009. Available: www.patientsafetyinstitute.ca /en/toolsResources/Research/commissionedResearch/EconomicsofPatientSafety /Documents/Economics\%20of\%20Patient\%20Safety\%20Literature\%20Review .pdf (accessed 2018 Apr. 30).

16. Wardle G, Wodchis WP, Laporte A, et al. The sensitivity of adverse event cost estimates to diagnostic coding error. Health Serv Res 2012;47:984-1007.

17. Kjellberg J, Wolf RT, Kruse M, et al. Costs associated with adverse events among acute patients. BMC Health Serv Res 2017;17:651.

18. Guilcher SJT, Bronskill SE, Guan J, et al. Who are the high-cost users? A method for person-centred attribution of health care spending. PLoS One 2016;11:e0149179.

19. Porter ME. A strategy for health care reform - toward a value-based system. N Engl J Med 2009;361:109-12.

20. Juurlink D, Preyra C, Croxford R, et al. Canadian Institute for Health information Discharge Abstract Database: a validation study - ICES investigative report. Toronto: Institute for Clinical Evaluative Sciences; 2006. Available: www.ices.on. ca/flip-publication/canadian-istitute-for-health-information-discharge/index.html (accessed 2018 May 6).

21. Wodchis WP, Austin PC, Henry DA. A 3-year study of high-cost users of health care. CMAJ 2016;188:182-8

22. Mondor L, Maxwell CJ, Hogan DB, et al. Multimorbidity and healthcare utilization among home care clients with dementia in Ontario, Canada: a retrospective analysis of a population-based cohort. PLoS Med 2017;14:e1002249.

23. Gruneir A, Bronskill SE, Maxwell CJ, et al. The association between multimor bidity and hospitalization is modified by individual demographics and physician continuity of care: a retrospective cohort study. BMC Health Serv Res 2016;16:154.

24. Pincus $D$, Wasserstein $D$, Nathens $A B$, et al. Direct medical costs of motorcycle crashes in Ontario. CMAJ 2017;189:E1410-5.

25. Pincus D, Ravi B, Wasserstein D, et al. Association between wait time and 30-day mortality in adults undergoing hip fracture surgery. JAMA 2017;318: 1994-2003.

26. Data quality study of the 2015-2016 Discharge Abstract Database: a focus on hospital harm. Ottawa: Canadian Institute for Health Information; 2016. Available: https://secure.cihi.ca/free_products/DAD_15_16_Reab_Report_EN.pdf (accessed 2019 Apr. 29).

27. Wodchis WP, Bushmeneva K, Nikitovic M, et al. Guidelines on person-level costing using administrative databases in Ontario. Working Paper Series Vol. 1. Toronto: Health System Performance Research Network; 2013. Available: www.hsprn.ca/ activities/papers/hsprn_case_costing_vol1_2013.pdf (accessed 2018 May 7).

28. Tanuseputro P, Wodchis WP, Fowler R, et al. The health care cost of dying: a population-based retrospective cohort study of the last year of life in Ontario, Canada. PLoS One 2015;10:e0121759. 
29. Gilbert T, Neuberger J, Kraindler J, et al. Development and validation of a Hospital Frailty Risk Score focusing on older people in acute care settings using electronic hospital records: an observational study. Lancet 2018;391:1775-82.

30. Austin PC. Using the standardized difference to compare the prevalence of a binary variable between two groups in observational research. Commun Stat Simul Comput 2009;38:1228-34.

31. Manning WG, Mullahy J. Estimating log models: To transform or not to transform? J Health Econ 2001;20:461-94.
32. Thavorn K, Maxwell CJ, Gruneir A, et al. Effect of socio-demographic factors on the association between multimorbidity and healthcare costs: a populationbased, retrospective cohort study. BMJ Open 2017;7:e017264.

33. Wang $\mathrm{R}$, Ware JH. Detecting moderator effects using subgroup analyses. Prev Sci 2013;14:111-20.

34. Rafter N, Hickey A, Condell S, et al. Adverse events in healthcare: learning from mistakes. QJM 2015;108:273-7.

\section{Competing interests: None declared.}

This article has been peer reviewed.

Affiliations: Institute of Health Policy, Management and Evaluation (Tessier, Guilcher, Bai, Ng, Wodchis), University of Toronto; Health System Performance Research Network (Tessier); Leslie Dan Faculty of Pharmacy (Guilcher), University of Toronto; ICES (Bai, $\mathrm{Ng}$ ), Toronto, Ont.; Institute for Better Health (Wodchis), Trillium Health Partners, Mississauga, Ont.

Contributors: All authors contributed to the study design (exposure and outcome measure conceptualization). Sara Guilcher, Yu Qing Bai and Walter Wodchis contributed to the data acquisition. Yu Qing Bai performed the data analysis. All of the authors contributed to the data interpretation. Lauren Tessier drafted the manuscript, which all authors revised. All of the authors approved the final version to be published and agreed to be accountable for all aspects of the work.

Funding: This research was supported by a grant from the Ontario Ministry of Health and Long-Term Care (MOHLTC) to the Health System Performance Research Network (fund \#06034, recipient W.P.W.), and by ICES, which is also funded by an annual grant from the Ontario MOHLTC. The opinions, results and conclusions reported in this paper are those of the authors and are independent from funding sources. No endorsement by ICES or the Ontario MOHLTC is intended or should be inferred. Parts of this material are based on data and information compiled and provided by the Canadian Institute for Health Information (CIHI). However, the analyses, conclusions, opinions and statements expressed herein are those of the authors, and not necessarily those of $\mathrm{ClHI}$. The authors thank $\mathrm{ClHI}$ for use of their hospital harm indicator. Sara Guilcher is supported by the Canadian Institutes for Health Research Embedded Clinician Scientist Salary Award in Transitions in Care.

Data sharing: The data from this study are held securely in coded form at ICES. Although data-sharing agreements prohibit ICES from making the data publicly available, access may be granted to those who meet prespecified criteria for confidential access (available at www.ices.on.ca/DAS).

Accepted: June 13, 2019

Correspondence to: Lauren Tessier, lauren.tessier@mail.utoronto.ca 